\title{
A política cultural: \\ regulação estatal e mecenato privado
}

\section{Maria Arminda do Nascimento Amuda}

$\mathrm{N}$ o amplo leque de concepções que nortearam a política cultural arquitetada pelo governo Fernando $\mathrm{H}$ enrique $\mathrm{C}$ ardoso, certos princípios sintetizaram de modo mais direto o espírito das ações programáticas implementadas. Tais princípios podem ser claramente discernidos nas frases de abertura de um texto de autoria do próprio ex-presidente:

Q uando artistas brasileiros se reúnem com o presidente da R epública, al guém com uma visão antiquada poderia imaginar uma pauta de queixas contra a desnacionalização cultural e pedidos de subsídios oficiais. N um encontro que tive recentemente no $\mathrm{R}$ io de Janeiro com um grupo do primeiro time de compositores e intérpretes da nossa música popular, as demandas foram outras, muito diferentes: presteza na regulamentação da nova lei de direitos autoraise mais repressão ao comércio de cd's piratas (C ardoso, 1998, p. 13).

Esse curto trecho exprime 0 ordenamento geral que guiou as formas de organização da cultura, assim como deixa a entrever o caráter do relacionamento dos gestores políticos com parte expressiva da comunidade dos artistas-intérpretes da música popular pertencentes ao "primeiro time" - bem como as diretrizesimplementadas ao longo dos oito anos do governo, sob a direção do ministro Francisco Weffort, que se responsabilizou pela pasta nos dois mandatos de Fernando $\mathrm{H}$ enrique $\mathrm{C}$ ardoso ${ }^{1}$. Al-

1. Entre 1985 e 1994, desde a criação do M inistério da Cultura no governo José Sarney até o fim do governo Itamar Franco, nove ministrosse sucederam na pasta, incluindo o período em que o $\mathrm{M} \mathrm{i-}$ nistério foi rebaixado à condição de Secretaria durante o governo Collor de M ello. 
guns sentidos podem ser percebidos na escrita do então presidente: 0 primeiro, refere-se à atribuição de postura antiquada à analogia entre cultura e nação; 0 segundo liga-se à idéia de que ao Estado caberia o financiamento da cultura, expectativa não assumida pelos criadores, 0 terceiro prende-se ao reconhecimento de que o papel do Estado é, fundamentalmente, 0 de regulação; o quarto exprime a aceitação por todos dos mecanismos do mercado, configurando-se, na verdade, na principal demanda dosprodutores; por último manifesta se certa expressão de apoio por parte dosartistas à política cultural em vigor, revelada na tran smissão de um clima que parece transpirar amistosidade.

Subjaz no texto uma acepção que parece organizar o conjunto, ou seja, a de que todas essas características reverberam uma atitude moderna, identificada com os novos tempos, atributos que embebiam a política cultural do governo, como se pode depreender das frases que se seguem poucosparágrafosapóso intróito:" muito ao contrário do nacionalismo xenófobo, eminentemente defensivo, essa cultura em ebulição inspira uma visão autoconfiante do B rasil em tempos de globalização" (C ardoso, 1998, p. 14).Assumida como a expressão mais vigorosa do mundo contemporâ neo, a globalização rejeita as formas do "nacionalismo xenófobo", impondo a atual idade inescapável da inserção da cultura na dinâmica internacional. Segundo 0 andamento proposto, 0 avanço em direção à modernidade globalizada pressupõe acatar tanto as transformações do papel do Estado como a conseqüente dinâmica do mercado, realidade que abrange as mais variadas dimensões da sociedade, movimento ao qual a cultura não tem como escapar e sequer deve furtar-se, condição mesma do seu compassamento com as tendências mundialmente mais avançadas. $\mathrm{H}$ á, em suma, na visão do presidente uma espécie de postulação de que a política em curso representava uma nova concepção de atividade intelectual e artística que se exprimia na organização dos assuntos culturais inaugurada no seu governo, identificada com concepções renovadas que plasmaram a ação pública na área.

Fernando $\mathrm{H}$ enrique $\mathrm{C}$ ardoso está dirigindo-se a interlocutores que, apesar de não estarem explicitamente nomeados, são figuras presentes no corpo das suas reflexões. $\mathrm{N}$ o plano mais imediato, os seus interlocutores são, naturalmente, os opositores à política cultural implementada; as referências mais afastadas dizem respeito às experiências passadas de ação governamental para o setor e que foram coroadas de êxito; o princípio que norteia a distinção do seu programa para os planos executados no 
passado reside na experiência de completa destruição do setor, ocorrida durante a curta presidência de Collor de M ello. Do ângulo da política global de governo, as posições manifestadas no texto aproximam-se do ideário neoliberal que distinguiu a sua gestão, sobretudo no transcurso do primeiro mandato (cf Sallum, 2000). R igorosamente falando, o texto do presidente filia-se à "crença na boa regulagem de mercado" (C astello, 2002, p. 654), combinada à ação disciplinadora do Estado.

U ma espécie de aproximação entre os mecanismos da economia e os processos culturais ronda as afirmações presentes no texto de Fernando H enrique, operando como divisor de águas a demarcar o ideário do seu governo, sintetizado na categoria globalização, vinculada à desregulamentação das relações econômicas, às transformações das relações entre os Estados nacionais. 0 ideal da modernidade aí pressuposto diz respeito à inserção necessária nessa dinâmica mundializada dos mercados. É por essa razão que os gestores da política cultural do governo Fernando $\mathrm{H}$ enrique $\mathrm{C}$ ardoso pensavam-se como marcadores de um novo tempo:

A relevância do mercado para a cultura e, de outro lado, a da cultura para 0 desenvolvimento econômico talvez sejam aí as mais significativas diferenças impostas pelaépoca atual às concepções de cultura, no B rasil, desde M ário deAndrade e dos pensadores dos anos 20 e 30 [...]. Diferentemente daquela época, porém, hoje é impossível deixar de reconhecer a relevância do mercado no campo da cultura, assim como a da cultura na economia (Weffort, 2000, pp. 64-65).

A sistemática em curso distinguiu-se, desse modo, dos procedimentos que dominaram, desde os anos de 1930, a política governamental destina da à cultura, uma vez que a ação normatizadora do Estado combinava-se ao papel indutor, de organização da área por intermédio dos mecanismos de financiamento.T radicionalmente concebidas como questão importante no rol das prioridades dos dirigentes brasileiros, sobretudo nos períodos de vigência dos regimes autoritários, as atividades culturais expandiram-se consideravelmente no transcurso do século XX. Paradigmática foi a relação tecida, por exemplo, entre Gustavo $C$ apanema e os intelectuais modernistas que conceberam a política cultural do Estado N ovo (cf. M iceli, 1979). A criação do Serviço do Patrimônio H istórico eArtístico N acional (SPH AN), idealizado por M ário deA ndrade e aprovado no Congresso por meio de decreto-lei, em dezembro de 1937, foi 
2. Por vezes, os colaboradores do ministro Weffort, na ânsia de demarcar a força das iniciativas, especialmente no âmbito da cinematografia, constroem uma imagem fortemente embebida na idéia de total renascimento (cf. R amos, 1998, pp. 103-120).

3. Asações desenvolvidasna gestão N ey Braga, no período da presidênciaErnesto Geisel, instituíram, pela primeira vez, uma política cultural dotada de caráter orgânico (cf. M iceli, 1984; Silva, 2001).
[...] um capítulo da história intelectual e institucional da geração modernista, um passo decisivo da intervenção governamental no âmbito da cultura e o lance acertado de um regime autoritário empenhado em construir uma “identidade nacional" iluminista no trópico dependente (M iceli, 2001, p. 360).

$\mathrm{N}$ aturalmente, o consórcio estabelecido entre os modernistas e a política cultural do Estado N ovo se não foi isento de tensões, marcou uma relação bem-sucedida entre os propósitos do ministro C apanema, que era um político de perfil ilustrado, e os intelectuais (cf. Schwartzman et al., 1984). A pesar do caráter conservador da modernização instaurada, em parte responsável por contradições que pontuavam a iniciativa, não há dúvida de que "a experiência de preservação do chamado 'patrimônio histórico e artístico nacional' constitui a política cultural mais bem-sucedida na área pública deste país" (M iceli, 2001, p. 359). 0 êxito inequívoco da política da cultura do M inistério Capanema pode ser dimensionado pela criação de uma concepção de cultura brasileira como uma dimensão fundamental, noção que passou a abrigar as mais diversas expressões, popularesou eruditas, produzidas no passado ou no presente. N ão é, portanto, casual que o ministro Francisco Weffort remeta se a esse momento para buscar a origem da política cultural ideada, significativamente, pela nata da intelectualidade brasileira. Vendo-se como herdeiro da melhor tradição, pois, a seu juízo, "no Brasil nunca houve, depois de 30, período no qual o país tenha aberto tantos caminhos de mudança como ocorre agora nos anos 90" (Weffort, 2000, p. 23), posicionava- se, simultaneamente, como promotor de marcante transformação².

0 estabelecimento, em suma, de laços de continuidade entre o período inaugural da política da cultura e a fase representada pela gestão Francisco Weffort tem como corolário o obscurecimento de iniciativas inovadoras, como as que foram implementadas durante o R egime M ilitar, quando da criação da Embrafilme em 1969, do Programa de Ação C ultural (PAC) em 1973 e do D epartamento de A ssuntosC ulturais(DAC ) em 1972, entre várias outras, apesar de terem ocorrido no momento mais repressivo do regime sob a presidência $M$ édici (cf. M iceli, 1984). Foi, no entanto, na direção de $\mathrm{N}$ ey B raga, à frente da pasta da E ducação, que a questão cultural recuperou a centralidade existente no passado, com a criação da Funarte, em 1975, ao lado de um conjunto de iniciativas que preparou a fundação do M inistério da C ultura, em 1985, no governo José Sarney, cuja organização ficou a cargo de um intelectual da estirpe de C elso Furtado ${ }^{3}$. A 
partir de então, a política cultural passou a ser assunto exclusivo de um órgão governamental, ainda quando foi devastada por ações de franca destruição de instituições longamente formadas, na ocasião do governo Collor de M ello ${ }^{4}$. A herança recebida pelo governo Fernando Henrique $C$ ardoso já se encontrava em plena recuperação, desde o retorno da Secretaria da C ultura - condição a que a pasta foi relegada por C ollor - à posição de ministério, em 1992, por Itamar Franco. C oncomitantemente, as leis de incentivos fiscais para a cultura, a chamada Lei Sarney, de 1986, reformada em 1991 pela denominada Lei R ouanet, bem como a Lei do Audiovisual, de 1993, tornaram-se os instrumentos privilegiados da gestão Weffort, e já encontravam- se em pleno funcionamento ${ }^{5}$.

Entre as primeiras medidas implantadas pela nova gestão, estava a modificação da Lei R ouanet, já em maio de 1995, apresentando as seguintes alterações: aumento de $2 \%$ para $5 \%$ do percentual de abatimento do imposto de renda de pessoas jurídicas para o patrocínio de projetos culturais; reconhecimento da figura do agente cultural na negociação dos projetos, cujos custos poderiam ser incluídosao orçamento; anulação do calendário para encaminhamento dos projetos, cuja aceitação passou a ocorrer ao longo de todo 0 ano; redução do prazo oficial de noventa para sessenta dias, dedicado à apreciação dos projetos (cf. B rasil, M inistério da C ultura, 1995).

Estava implantado, assim, um “mercado de patrocínios", intermediado pelos" agentes culturais". Profissionais capacitados para lidar com operações financeiras e dotados de conhecimentos sobre a área tributária, as finanças e o marketing... Ficava criado, assim, não só um mercado de bens culturais, mas um mercado de imagens institucionais (C astello, 2002, p. 636).

Em outrostermos, além de profissionalizar a figura do intermediário, a política em curso estimulou o aparecimento de nichos no mercado cultural, provocando a integração de setores até então bastante distantes da lógica mercantil, como era a situação das artes, do patrimônio, da cultura popular. Instaurou-se, desse modo, uma espécie de migração de procedimentostípicos da indústria cultural e do mercado publicitário. U ma análise das motivações empresariais para investir na cultura demonstra que os sentidos perseguidos do chamado marketing cultural são, em substância, coerentes sobretudo com as estratégias publicitárias e, secundariamente, com objetivos sociais ${ }^{6}$, respondendo pelo espantoso crescimento do mecenato privado (cf. M oisés, 1998, p. 438).
4. Para uma minuciosa reconstituição desse processo, cf. C astello, 2002.

5. José C astello (2002) é, novamente, a fonte mais completa sobre a questão.

6. M otivações das empresas parainvestimentos em cultura (cf. M oisés, 1998): ganho de imagem institucional (65,04\%); agregação de valor à marca da empresa $(27,64 \%)$; reforço do papel social da empresa $(23,58 \%)$; benefícios fiscais $(21,14 \%)$; retorno de mídia (6,5\%); aproximação do público-alvo (5,69\%); outro (3,25\%); não citou (11,38\%). $\mathrm{R}$ espostas múltiplas $\mathrm{e}$ não excludentes. 


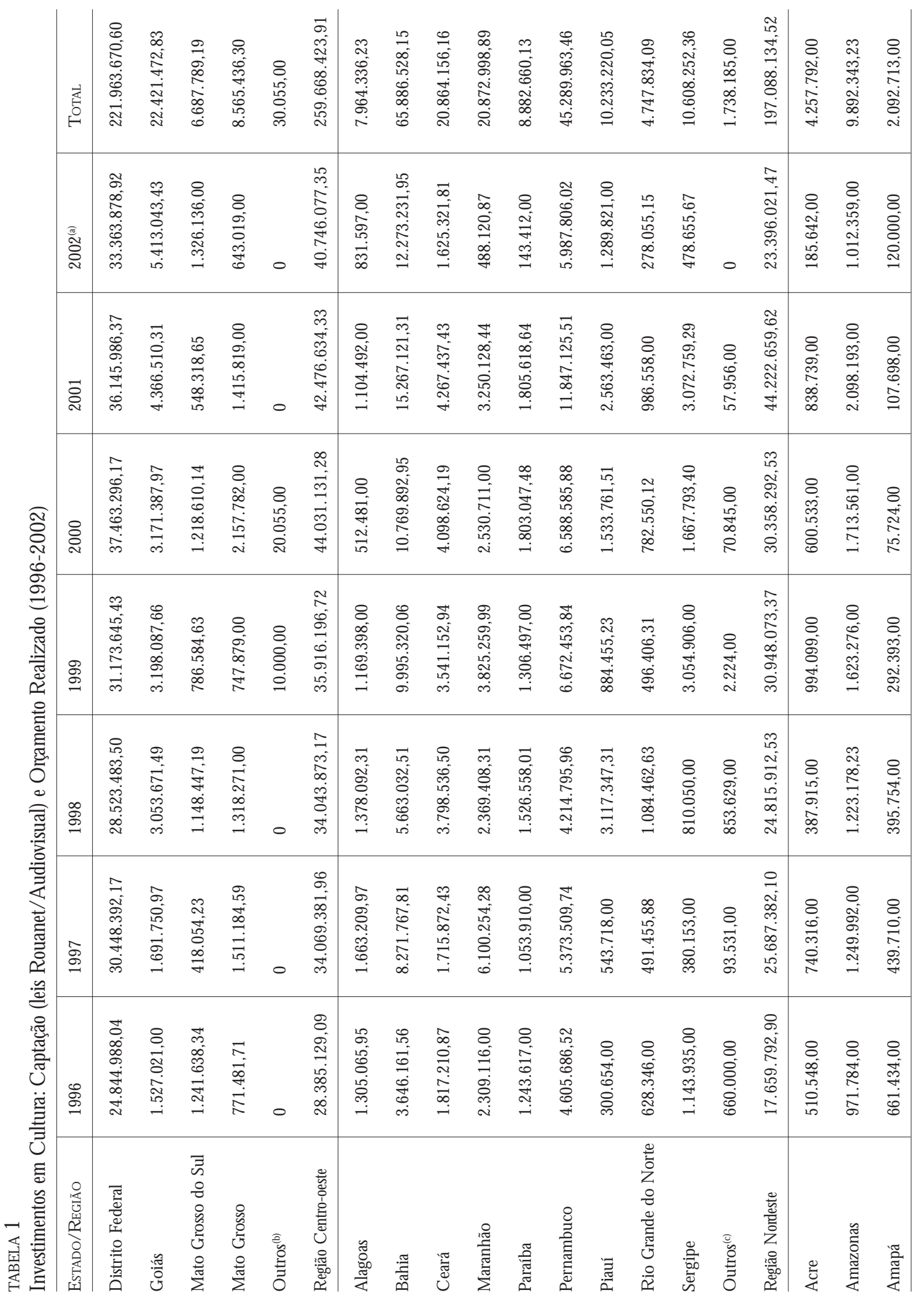




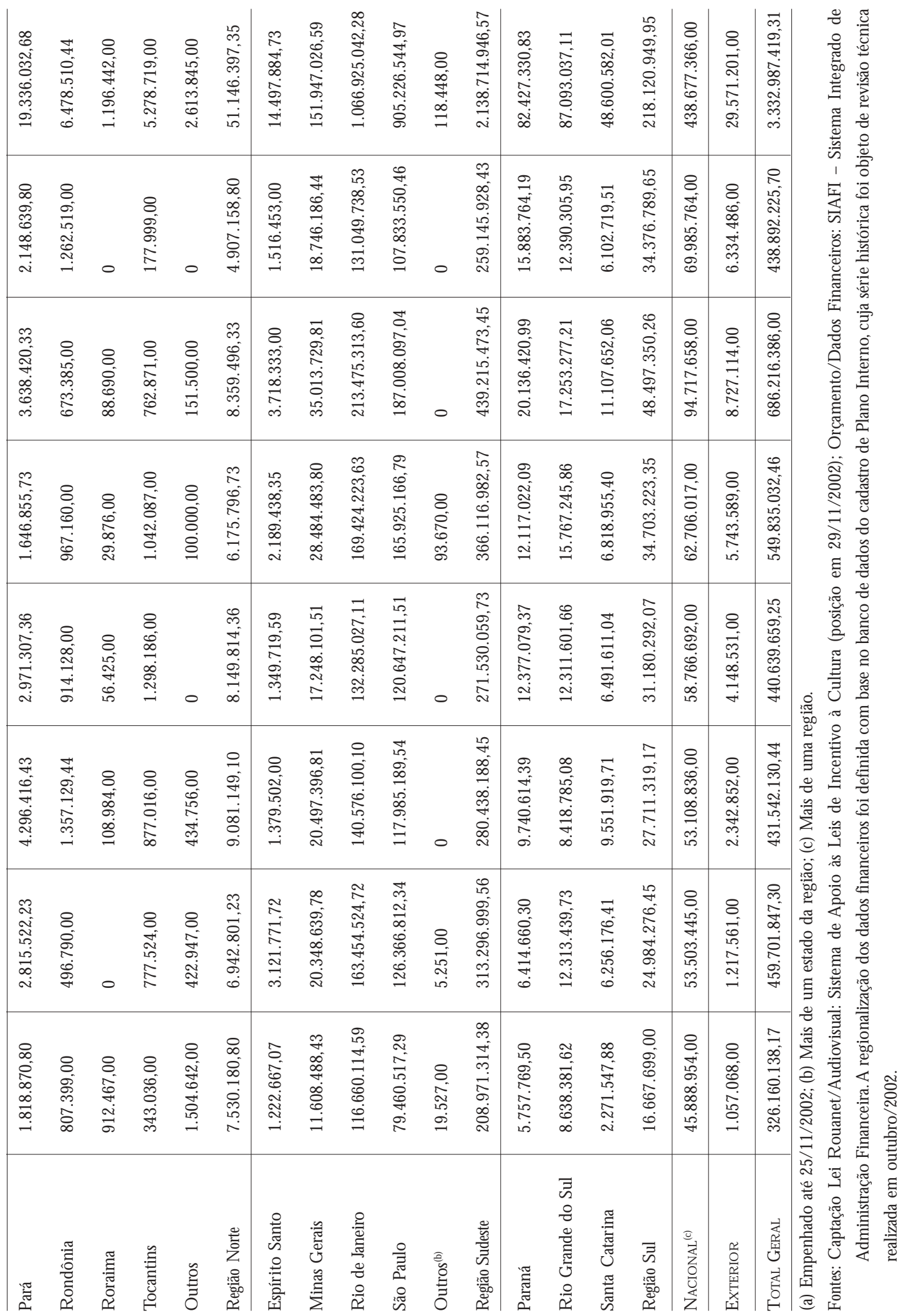


U ma análise do investimento global em cultura, no período entre 1996 e 2002, compreendendo recursos captados no mercado, oriundos da Lei $R$ ouanet de incentivos fiscais e aqueles provenientes da Lei do Audiovisual, referente ao orçamento efetivamente realizado, não deixa margem à dúvida sobre a tendência de crescimento dos investimentos na área. $\mathrm{N} \mathrm{a}$ avaliação do dispêndio dos recursos no plano regional reproduz-se a primazia do Sudeste; em segundo lugar, encontra-se o C entro- oeste, rompendo o critério de significação econômica que indicaria o Sul como 0 pólo seguinte. $\mathrm{N}$ o Sudeste, foi 0 estado do R io de Janeiro e não o de São Paulo que angariou mais recursos, deixando a entrever o poder de influência da comunidade carioca no âmbito federal (Tabela 1).

TABELA 2

Total de $P$ rojetos $A$ presentados por $L$ eis $F$ ederais de Incentivos à $C$ ultura, por segmento e ano (1996-2001)(a)

\begin{tabular}{|c|c|c|c|c|c|c|c|}
\hline Segmento & 1996 & 1997 & 1998 & 1999 & 2000 & 2001 & TOTAL \\
\hline Artes C ênicas & 436 & 710 & 737 & 821 & 759 & 970 & 4.433 \\
\hline Artes Integradas ${ }^{(b)}$ & 401 & 754 & 311 & 209 & 158 & 282 & 2.115 \\
\hline Artes Plásticas & 159 & 238 & 312 & 376 & 358 & 355 & 1.798 \\
\hline H umanidades & 347 & 539 & 706 & 921 & 748 & 730 & 3.991 \\
\hline M úsica & 413 & 823 & 916 & 871 & 850 & 960 & 4.833 \\
\hline Patrimônio Cultural & 217 & 273 & 313 & 417 & 260 & 303 & 1.783 \\
\hline Produção Audiovisual & 378 & 539 & 573 & 506 & 377 & 468 & 2.841 \\
\hline TOTAL & 2.351 & 3.876 & 3.868 & 4.121 & 3.510 & 4.068 & 21.794 \\
\hline \multicolumn{8}{|l|}{ LEI R OUAnet } \\
\hline Segmento & 1996 & 1997 & 1998 & 1999 & 2000 & 2001 & TOTAL \\
\hline Artes C ênicas & 436 & 710 & 737 & 821 & 759 & 970 & 4.433 \\
\hline Artes Integradas ${ }^{(b)}$ & 401 & 754 & 311 & 209 & 158 & 282 & 2.115 \\
\hline Artes Plásticas & 159 & 238 & 312 & 376 & 358 & 355 & 1.798 \\
\hline Humanidades & 347 & 539 & 706 & 921 & 748 & 730 & 3.991 \\
\hline M úsica & 413 & 823 & 916 & 871 & 850 & 960 & 4.833 \\
\hline Patrimônio Cultural & 217 & 273 & 313 & 417 & 260 & 303 & 1.783 \\
\hline Produção Audiovisual & 343 & 442 & 507 & 422 & 294 & 372 & 2.380 \\
\hline TOTAL & 2.316 & 3.779 & 3.802 & 4.037 & 3.427 & 3.972 & 21.333 \\
\hline \multicolumn{8}{|l|}{ LEI DO AUdIOVISUAL } \\
\hline Segmento & 1996 & 1997 & 1998 & 1999 & 2000 & 2001 & TOTAL \\
\hline Produção Audiovisual & 35 & 97 & 66 & 84 & 83 & 96 & 461 \\
\hline
\end{tabular}

(a) Posição de abril de 2002.

(b) M ais de um segmento.

F onte: Dados fornecidos pelo site do M inistério da Cultura. 
TABELA 3

Total de $P$ rojetos A provados por L eis F ederais de Incentivos à C ultura, por segmento e ano (1996-2001) (a) (em milhões de reais)

\begin{tabular}{|c|c|c|c|c|c|c|c|}
\hline \multicolumn{8}{|c|}{ LEIS R OUANET E DO Audiovisual } \\
\hline Segmento & 1996 & 1997 & 1998 & 1999 & 2000 & 2001 & TOTAL \\
\hline Artes C ênicas & 300 & 586 & 719 & 688 & 668 & 762 & 3.723 \\
\hline Artes Integradas ${ }^{(b)}$ & 264 & 499 & 338 & 127 & 110 & 155 & 1.493 \\
\hline Artes Plásticas & 126 & 179 & 304 & 254 & 301 & 328 & 1.492 \\
\hline H umanidades & 271 & 309 & 598 & 740 & 525 & 416 & 2.859 \\
\hline M úsica & 308 & 640 & 832 & 723 & 590 & 641 & 3.734 \\
\hline Patrimônio Cultural & 141 & 193 & 231 & 233 & 150 & 162 & 1.110 \\
\hline Produção Audiovisual & 278 & 463 & 476 & 317 & 269 & 233 & 2.036 \\
\hline TOTAL & 1.688 & 2.869 & 3.498 & 3.082 & 2.613 & 2.697 & 16.447 \\
\hline \multicolumn{8}{|l|}{ LeI R OUAnet } \\
\hline Segmento & 1996 & 1997 & 1998 & 1999 & 2000 & 2001 & TOTAL \\
\hline Artes C ênicas & 300 & 586 & 719 & 688 & 668 & 762 & 3.723 \\
\hline Artes Integradas ${ }^{(b)}$ & 264 & 499 & 338 & 127 & 110 & 155 & 1.493 \\
\hline Artes Plásticas & 126 & 179 & 304 & 254 & 301 & 328 & 1.492 \\
\hline H umanidades & 271 & 309 & 598 & 740 & 525 & 416 & 2.859 \\
\hline M úsica & 308 & 640 & 832 & 723 & 590 & 641 & 3.734 \\
\hline Patrimônio Cultural & 141 & 193 & 231 & 233 & 150 & 162 & 1.110 \\
\hline Produção Audiovisual & 243 & 367 & 415 & 260 & 214 & 161 & 1.660 \\
\hline TOTAL & 1.653 & 2.773 & 3.437 & 3.025 & 2.558 & 2.625 & 16.071 \\
\hline \multicolumn{8}{|l|}{ LEI DO AUDIOVISUAL } \\
\hline Segmento & 1996 & 1997 & 1998 & 1999 & 2000 & 2001 & TOTAL \\
\hline Produção Audiovisual & 35 & 96 & 61 & 57 & 55 & 72 & 376 \\
\hline
\end{tabular}

(a) Posição de abril de 2002.

(b) M ais de um segmento.

Fonte: $\mathrm{D}$ ados fornecidos pelo site do M inistério da Cultura.

PelaTabela 2 pode-se perceber 0 universo de projetos apresentados no período de 1996 a 2001, discriminados por setor, segundo modalidades de demandas por financiamento - Lei R ouanet e Lei do Audiovisual. A tendência ao crescimento é nítida, a despeito de flutuações terem ocorrido principalmente entre os anos de 1999 e 2000. As artes cênicas dominam em termos de volume, seguidas pela área musical, situação que se repete quando se consideram os projetos aprovados, como se depreende da Tabela 3. 0 s recursos dirigidos principalmente à área teatral foram responsáveis pela grande dinamização do setor, o que vem acontecendo do mesmo modo no campo da música com a implementação, a partir de 1996, do Programa de Bandas (cf. Peixoto, 1998). 


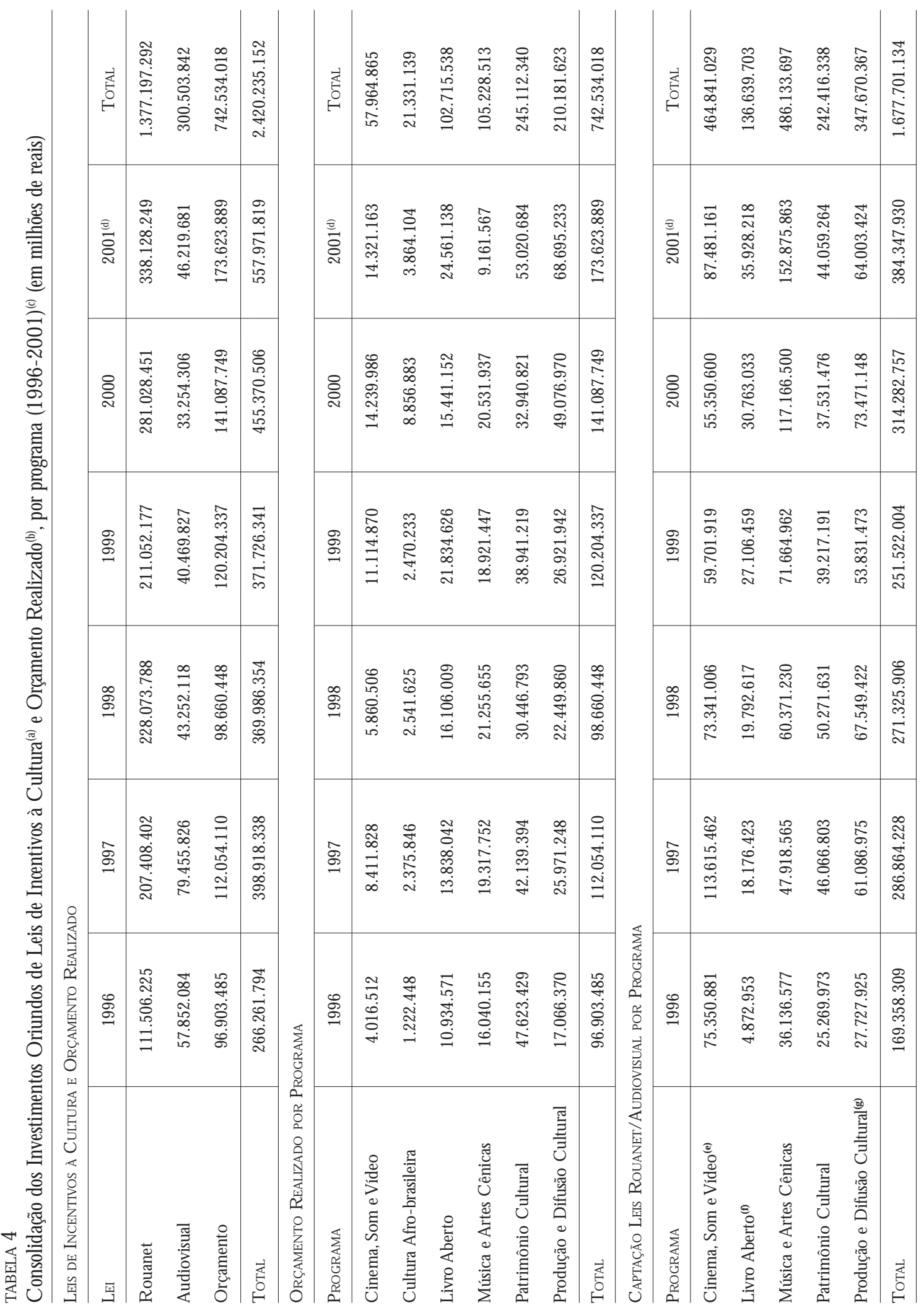




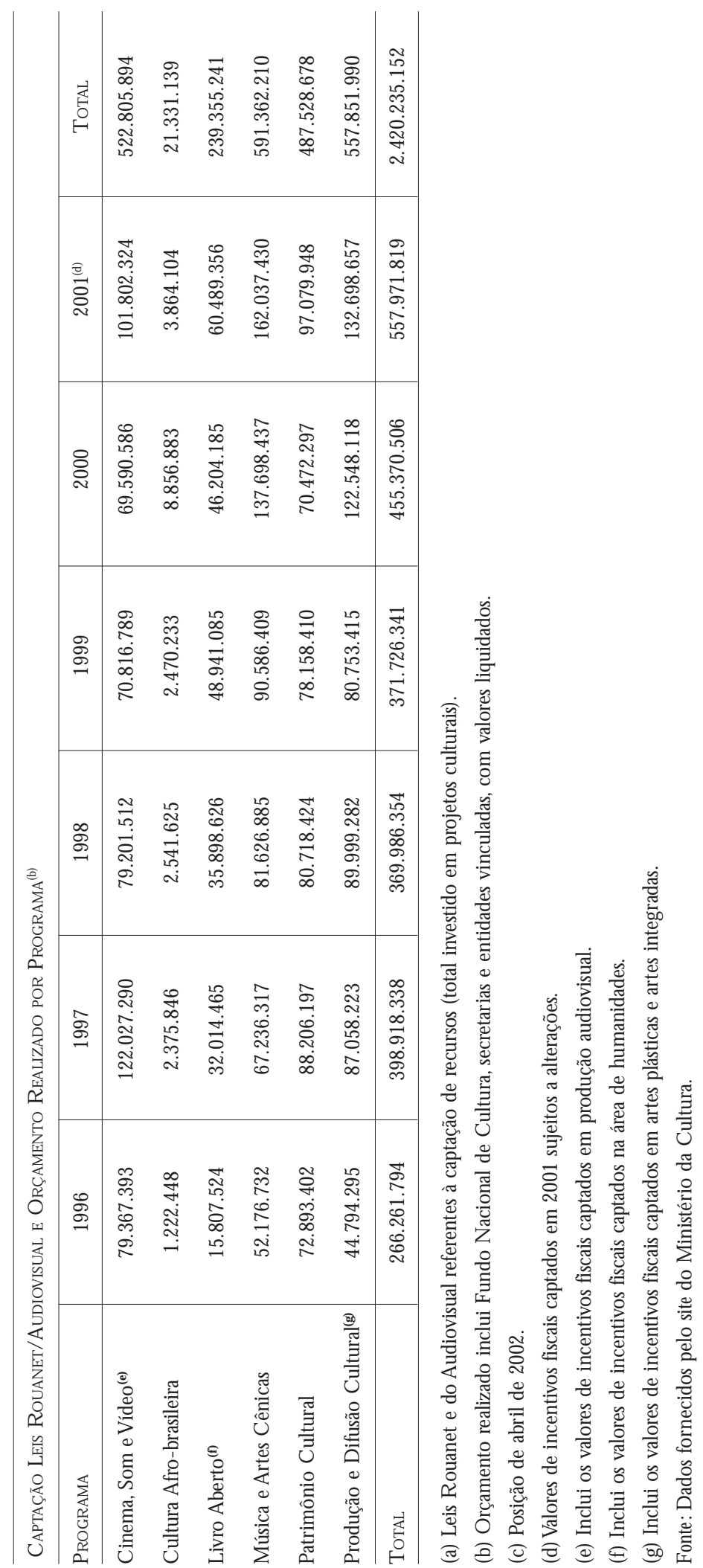


O s dados relativos à consolidação dos investimentos em cultura, globalmente tratados, revelam que a Lei R ouanet de incentivo à cultura foi o suporte do financiamento, uma vez que respondeu pelo maior volume dos investimentos, estando muito além dos recursos provenientes do orçamento. D epreende-se da análise que o M inistério da C ultura concentrou sua política no incentivo à captação de recursos no mercado e na promoção das iniciativas ligadas ao chamado marketing cultural. Enquanto 0 orçamento tem um crescimento próximo da atualização de valores, os recursos provenientes das leis de incentivo revelam crescimento visível. É digno de nota que o maior volume de recursos oriundos do orçamento dirigiramse para os programas à margem do mercado, como patrimônio cultural ea produção e difusão cultural. Segundo essa lógica, tende a crescer no período os projetos financiados por meio da captação de recursos no mercado. 0 s dados globais exprimem, desse modo, o cerne da ação cultural do governo Fernando $\mathrm{H}$ enrique $\mathrm{C}$ ardoso, esclarecendo-se os sentidos presentes na articulação discursiva centrada nas" questões de financiamento, tributação, isenção fiscal e marketing empresarial" (C astello, 2002, p. 656).

0 espírito da política cultural no período nutriu-se da função regula mentadora, uma vez que coube aos gestores do ministério o papel de intermediários e de avalizadores do processo - expresso no julgamento de mérito dos projetos apresentados, acompanhado da atitude de estimulação e de incentivo, desenvolvendo o exercício normatizador, tornando a atividade pública um meio de aproximação dos agentes no campo da cultura. 0 aparente laissez -faire, todavia, alimentou-se, a rigor, da transferência de recursos, uma vez que a lei de incentivo troca pagamentos de impostos - que poderiam ser aplicados de modo diverso - por investimento cultural. Se os produtores culturais são beneficiários inequívocos da política implementada, igualmente o são osorganismos privados quando podem se utilizar do marketing cultural, com os efeitos previsíveis de valorização da imagem das empresas envolvidas. Instalou-se uma certa peda gogia no âmbito da cultura que produziu o disciplinamento dos agentes, criou funções, e vem despertando uma ética muito peculiar na esfera do financiamento privado, uma vez que é o Estado o normatizador, mas sobretudo a instância a repassar os recursos, embora de forma indireta. $\mathrm{N}$ ão se está, no entanto, diante de repetição de modelos embasados no típico mecenato privado, sequer é possível aproximá lo de iniciativas pioneiras como as que se desenrolaram na cidade de São Paulo no meio de século XX (cf. Arruda, 2001). 
TABELA 5

Total de P rojetos com C aptação de R ecursos por L eis F ederais de Incentivos à C ultura, por segmento e ano (1996-2001)(a)

Leis R ouanet e do Audiovisual

\begin{tabular}{|c|c|c|c|c|c|c|c|}
\hline Segmento & 1996 & 1997 & 1998 & 1999 & 2000 & 2001 & TOTAL \\
\hline Artes C ênicas & 78 & 124 & 150 & 166 & 239 & 315 & 1.072 \\
\hline Artes Integradas(b) & 60 & 124 & 127 & 77 & 49 & 51 & 488 \\
\hline Artes Plásticas & 36 & 61 & 91 & 90 & 91 & 110 & 479 \\
\hline H umanidades & 65 & 107 & 143 & 178 & 232 & 207 & 932 \\
\hline M úsica & 68 & 110 & 161 & 198 & 221 & 217 & 975 \\
\hline Patrimônio Cultural & 64 & 97 & 129 & 129 & 136 & 112 & 667 \\
\hline Produção Audiovisual & 146 & 224 & 209 & 210 & 180 & 189 & 1.158 \\
\hline TOTAL & 517 & 847 & 1.010 & 1.048 & 1.148 & 1.201 & 5.771 \\
\hline
\end{tabular}

LeI R OUANET

\begin{tabular}{|c|c|c|c|c|c|c|c|}
\hline Segmento & 1996 & 1997 & 1998 & 1999 & 2000 & 2001 & TOTAL \\
\hline Artes C ênicas & 78 & 124 & 150 & 166 & 239 & 315 & 1.072 \\
\hline Artes Integradas ${ }^{(b)}$ & 60 & 124 & 127 & 77 & 49 & 51 & 488 \\
\hline Artes Plásticas & 36 & 61 & 91 & 90 & 91 & 110 & 479 \\
\hline H umanidades & 65 & 107 & 143 & 178 & 232 & 207 & 932 \\
\hline M úsica & 68 & 110 & 161 & 198 & 221 & 217 & 975 \\
\hline Patrimônio Cultural & 64 & 97 & 129 & 129 & 136 & 112 & 667 \\
\hline Produção Audiovisual & 39 & 61 & 64 & 64 & 64 & 87 & 379 \\
\hline TOTAL & 410 & 684 & 865 & 902 & 1.032 & 1.099 & 4.992 \\
\hline
\end{tabular}

LEI DO AUDIOVISUAL ${ }^{(c)}$

\begin{tabular}{l|c|c|c|c|c|c|c}
\hline SEgmento & 1996 & 1997 & 1998 & 1999 & 2000 & 2001 & TOTAL \\
\hline Produção Audiovisual & 107 & 163 & 145 & 146 & 116 & 102 & 779 \\
\hline
\end{tabular}

(a) Posição de abril de 2002.

(b) M ais de um segmento.

(c) O s quantitativos incluem projetos aprovados em anos anteriores e com captação de recursos em mais de um exercício fiscal.

F onte: D ados fornecidos pelo site do M inistério da Cultura.

D urante o governo Fernando $\mathrm{H}$ enrique $\mathrm{C}$ ardoso, o panorama da cultura transformou-se, certamente, so b o comando sistemático dosmecanismos de financiamento antes inusuais no Brasil. H erdeiro indireto de uma "terra arrasada", mas que recomeçava a se reorganizar, a política do período FHC só poderia ser saudada com efusividade, desconcertando mesmo os críticos mais renitentes. $N$ ão se chegou a avaliar de modo mais profundo os efeitos possíveis dessa política, até porque o processo está em cursoํ․

7. Há certa avaliação do período em Castello (2002). 
A política cultural: regulação estatal e mecenato privado

TABELA 6

C onsolidação da C aptação de R eaursos por L eis F ederais de Incentivos à C ultura, por segmento e ano (1996-2001) (a) (em milhões de reais)

Leis R OUAnet/Audiovisual

\begin{tabular}{l|c|c|c|c|c|c|c}
\hline SEGM ENTO & 1996 & 1997 & 1998 & 1999 & 2000 & $2001^{(\mathrm{b})}$ & TOTAL \\
\hline Artes Cênicas & 15.779 .753 & 22.731 .059 & 22.314 .735 & 29.426 .655 & 58.600 .555 & 77.153 .984 & 226.006 .741 \\
Artes Integradas ${ }^{(c)}$ & 20.418 .816 & 49.150 .050 & 44.393 .450 & 35.953 .172 & 40.847 .253 & 39.048 .437 & 229.811 .178 \\
Artes Plásticas & 7.309 .109 & 11.936 .925 & 23.155 .972 & 17.878 .301 & 32.623 .895 & 24.954 .987 & 117.859 .189 \\
H umanidades & 4.872 .953 & 18.176 .423 & 19.792 .617 & 27.106 .459 & 30.763 .033 & 35.928 .218 & 136.639 .703 \\
M úsica & 20.356 .824 & 25.187 .506 & 38.056 .495 & 42.238 .307 & 58.565 .945 & 75.721 .879 & 260.126 .956 \\
Patrimônio Cultural & 25.269 .973 & 46.066 .803 & 50.271 .631 & 39.217 .191 & 37.531 .476 & 44.059 .264 & 242.416 .338 \\
Produção Audiovisual & 75.350 .881 & 113.615 .462 & 73.341 .006 & 59.701 .919 & 55.350 .600 & 87.481 .161 & 464.841 .029 \\
\hline TotAL & 169.358 .309 & 286.864 .228 & 271.325 .906 & 251.522 .004 & 314.282 .757 & 384.347 .930 & 1.677 .701 .134 \\
\hline
\end{tabular}

LeI R OUANET

\begin{tabular}{l|c|c|c|c|c|c|c}
\hline SEGM EN TO & 1996 & 1997 & 1998 & 1999 & 2000 & $2001^{(b)}$ & TotAL \\
\hline Artes Cênicas & 15.779 .753 & 22.731 .059 & 22.314 .735 & 29.426 .655 & 58.600 .555 & 77.153 .984 & 226.006 .741 \\
Artes Integradas(c) & 20.418 .816 & 49.150 .050 & 44.393 .450 & 35.953 .172 & 40.847 .253 & 39.048 .437 & 229.811 .178 \\
Artes Plásticas & 7.309 .109 & 11.936 .925 & 23.155 .972 & 17.878 .301 & 32.623 .895 & 24.954 .987 & 117.859 .189 \\
H umanidades & 4.872 .953 & 18.176 .423 & 19.792 .617 & 27.106 .459 & 30.763 .033 & 35.928 .218 & 136.639 .703 \\
M úsica & 20.356 .824 & 25.187 .506 & 38.056 .495 & 42.238 .307 & 58.565 .945 & 75.721 .879 & 260.126 .956 \\
Patrimônio Cultural & 25.269 .973 & 46.066 .803 & 50.271 .631 & 39.217 .191 & 37.531 .476 & 44.059 .264 & 242.416 .338 \\
Produção Audiovisual & 17.498 .797 & 34.159 .636 & 30.088 .888 & 19.232 .092 & 22.096 .294 & 41.261 .480 & 164.337 .187 \\
\hline T otAL & 111.506 .225 & 207.408 .402 & 228.073 .788 & 211.052 .177 & 281.028 .451 & 338.128 .249 & 1.377 .197 .292 \\
\hline
\end{tabular}

LEI DO Audiovisual

\begin{tabular}{l|c|c|c|c|c|c|c}
\hline SEGMENTO & 1996 & 1997 & 1998 & 1999 & 2000 & $2001^{(b)}$ & TOTAL \\
\hline Produção Audiovisual & 57.852 .084 & 79.455 .826 & 43.252 .118 & 40.469 .827 & 33.254 .306 & 46.219 .681 & 300.503 .842 \\
\hline
\end{tabular}
(a) Posição de abril de 2002.
(b) Valores de incentivos fiscais captados em 2001 e sujeitos a alterações.
(c) M ais de um segmento.

F onte: D ados fornecidos pelo site do M inistério da Cultura.

0 crescimento das iniciativas em todos os ramos da criação expressa que há um movimento de expansão do campo cultural, o que não significa ipso fado maior complexidade no âmbito das linguagens, podendo ser pura reprodução de estilos consagrados pela harmonia do gosto médio. 0 que não é mal de per se, ainda que não convide à aventura, não freqüente 0 desconhecido. 0 chamado "cinema da retomada" - termo carregado de sentidos - , se demonstra o crescimento do número de filmes lançados no 
país, não esclarece a qual tradição se está referindo ${ }^{8}$. A o que se recuperou, impõe-se a pergunta: a tradição experimental do $\mathrm{C}$ inema $\mathrm{N}$ ovo ou apenas a volta do interesse pelo mercado de filmes?

A perspectiva do governo sobre a cultura explicitou-se em certas expressões doutrinárias entendidas, pelos gestores da política na área, como tendo desencadeado "uma pequena revolução cultural" . N a execução das propostas, postulou-se que

[...] o M inistério da Cultura enfrentou as duas mentalidades aferradas ao passado e, ao mesmo tempo, estimulou a formação de uma visão empresarial moderna, segundo a qual as vantagens dos incentivosfiscais para a cultura devem associar-se tanto ao marketing cultural como a um claro compromisso das empresas com a sua comunidade (M oisés, 1998, p. 422).

A visão pedagógica subjacente segue alguns postulados que domina vam a cena da história no fim do século XX, reunidos no ideário que reconhece a superioridade da lógica do mercado na organização das relações sociais, desembocando na naturalização dasaçõeseconômicas, aceitas como princípios universais e incontestáveis. A particularidade intrínseca ao ato de produção cultural não se esquivou da universalidade abstrata das leis de mercado no trânsito do último decênio, embora os efeitos da política cultural vigente não tenham sido idênticosa todos osramosda produção cultural.

\section{Referências Bibliográficas}

ArRuda, M aria Arminda do N ascimento. (2001), M etrópole e cultura: São Paulo no meio século XX. Bauru, Edusc.

BrasIL. M inistério da Cultura. (1995), "R elatório de 1995”. Braślia, M inistério da Cultura.

B R ASIL. M inistério da Cultura. Secretaria do Audiovisual. (1999), [site do M inistério da C ultura] Brasília.

BrasIL. M inistério da Cultura. (2002), Sistema de apoio às leis de incentivo à aultura. Brasília, M inistério da Cultura.

CARdoso, Fernando Henrique. (1998), "Prefácio: sem medo nem saudade". In: W EFFoRT, Francisco \& Souza, M árcio. (orgs.), U m olhar sobre a cultura brasileira, B rasília, M inistério da C ultura, pp. 13-14.
8. Entre 1990 e 1999, segundo a Secretaria do Audiovisual (Brasil, 1999), o número de filmeslançadosnacionalmente foi: sete, em 1990; oito, em 1991; três, em 1992; quatro, em 1993; sete, em 1994; doze, em 1995; 23, em 1996; 22, em 1997; 26, em 1998; e 25, em 1999. 
C astello, José. (2002), “C ultura”. In: Lam ounier , Bolívar \& Figueir edo, R ubens(orgs).

A era F H C : um balanço, São Paulo, C ultura EditoresA ssociados, pp.627-656.

M ICELI, Sergio. (1979), Intelectuais e classe dirigente no B rasil (1920-1945). São Paulo, Difel.

. (1984), “O Processo de'construção intelectual' na área cultural federal (anos 70)". In: . (org.). E stado e aultura no B rasil, São Paulo, Difel. . (2001), "SPH AN : refrigério da cultura oficial". In: Intel ectuais à

brasileira, São Paulo, Cia. das Letras, pp. 357-368.

M o IsÉs, José Á Ivaro. (1998), "O s efeitos das leis de incentivo”. In: W EFFO RT, Francis$\mathrm{co} \&$ So uzA, M árcio (orgs.). U m olhar sobre a aultura brasileira, Braślia, M inistério da C ultura, pp. 445-462.

. (2001), M otivações das empresas para incentivos em altura. Belo Horizonte, Fundação João Pinheiro.

Peix oto,Valéria R ibeiro. (1998), “M usica clássica, bandas”. In: W effort, Francisco \& So uzA, M árcio (orgs.). U m olhar sobre a altura brasileira, Braślia, M inistério da Cultura, pp. 261-274.

R Am o S, Luciano. (1998), “O sfilmes - a retomada”. In: W efFo RT, Francisco \& So uzA, M árcio (orgs.). U m olhar sobre a cultura brasileira, B rasília, M inistério da C ultura, pp. 103-120.

Sallum JR ., Brasilio. (2000), "O Brasil sob C ardoso: neoliberalismo e desenvolvimentismo". Tempo Sodal, 11 (2): 23-48, São Paulo.

Schwartzman, Simon et al. (1984), Tempos de C apanema. São Paulo, Paz e Terral Edusp.

SILva, Vanderli M aria da. (2001), A construção da política cultural no regime militar: concepções, diretriz es e programas (1974-1978). Dissertação de mestrado, São PauIo, FFLCH -U SP.

W EFFo RT, Francisco. (2000), A cultura e as revoluçoes da moderniz ação. $R$ io de Janeiro, Fundo $\mathrm{N}$ acional de $\mathrm{C}$ ultura.

\section{Resumo}

0 artigo traça as diretrizes da política cultural implementada durante 0 segundo governo FH C : leis de incentivo fiscal, financiamento privado e regulação estatal. A ação cultural do governo atribuiu ao Estado o papel de intermediário no processo de financiamento, avalizando relações entre produtores culturais e agentes econômicos. Em lugar de um típico mecenato privado, instituiu-se uma nova modalidade de promoção cultural. A expansão das iniciativas nos diversos ramos da criação cultural não significou, necessariamente, a renovação das linguagens. 
Palavras-chave: Política cultural; M ecenato privado e governamental; Incentivos, subvenções e renúncia fiscal.

\begin{abstract}
This paper traces the guidelines of the cultural policies prevailing during Fernando $\mathrm{H}$ enrique C ardoso's second term of government: fiscal incentive legislation, private funding and state regulation. The government's cultural action designed the state as regulator, acting as "go-between" towards the cultural producers and the new economic agents. Instead of a typical private patronage model, the state instituted a new kind of cultural promotion.The expansion of initiatives in every domain of cultural creation did not mean, necessarily, the renewal of languages.
\end{abstract}

Key words: Cultural policy; Private and governmental art funding; Incentives; subventions and fiscal waivers.

M aria Arminda do $\mathrm{N}$ ascimento Arruda é professoralivre-docente do Departamento de Sociologia da Faculdade de Filosofia, L etras e C iências H umanas da U SP e secretária-executiva da Associação N acional de Pós-Graduação e Pesquisa em C iências Sociais (Anpocs). 